\title{
Quantitative determination of major oxidation products in edible oils by direct NP-HPLC-DAD analysis
}

Joaquín Velasco ${ }^{1, *}$, Arturo Morales ${ }^{1}$, M. Victoria Ruiz-Méndez ${ }^{1}$ and Gloria Márquez-Ruiz ${ }^{2}$

${ }^{1}$ Instituto de la Grasa, Consejo Superior de Investigaciones Científicas (CSIC),

Campus Universidad Pablo de Olavide, Ctra. de Utrera, km 1, E-41013 Sevilla, Spain

${ }^{2}$ Instituto de Ciencia y Tecnología de Alimentos y Nutrición, Consejo Superior de Investigaciones Científicas (CSIC), c/ José Antonio Novais, 10, E-28040 Madrid, Spain

*To whom correspondence should be addressed:

Telephone: +34954611550

Fax: $\quad+34954616790$

E-mail: jvelasco@ig.csic.es

Running title: Direct quantification of major oxidation products in oils by HPLC 


\section{Abstract}

2 The objective of the present study was to explore the possibilities of the direct analysis of

3 vegetable oils by normal-phase HPLC-DAD to evaluate the amounts of the main oxidation

4 products of triacylglycerols containing linoleate, i.e. hydroperoxy-, keto- and hydroxy-dienes.

5 A follow-up of oxidation at $40{ }^{\circ} \mathrm{C}$ of trilinolein, used as a simplified model lipid system, high-

6 linoleic sunflower oil and high-oleic sunflower oil was performed to evaluate samples with

7 different fatty acid compositions and different oxidation levels. The results showed that the

8 HPLC-DAD method proposed allows for determining the concentrations of mono-

9 hydroperoxydienes in edible oils without applying any isolation or derivatization step. The

10 method was found to be direct, sensitive (LOQ $0.06 \mathrm{mmol} / \mathrm{kg}$ oil), precise $(\mathrm{CV} \leq 5 \%)$ and

11 also accurate, with $99 \%$ of analyte recovery. It also enabled the estimation of the minor

12 amounts of ketodienes, but not those of hydroxydienes, which presented wide

13 chromatographic bands and coeluted with a number of different minor oxidation compounds.

14 Key-words: Hydroperoxydienes; ketodienes; hydroxydienes; oils; autoxidation; HPLC 


\section{Introduction}

Autoxidation of food lipids causes a variety of products that eventually impair the food flavor and make the food unacceptable for consumption. Oxidized lipids are also involved in pathophysiological processes of chronic and degenerative diseases [1-6]. These can be incorporated through the diet, be formed during the digestion of lipids or be produced in the body, especially in unhealthy individuals. Oxidized food lipids are therefore of concern because they may be detrimental to health. Numerous nutritional studies evidence the toxicological effects of oxidized oils [2, 7-10]. Unfortunately, in most of these studies the characterization of oxidized oils was deficient. This was performed by applying analytical indices such as the peroxide value, anisidine value and others that only provide information about partial aspects of the oxidative degradation. Thereby such indices do not enable to get to know the real oil oxidation state and, more importantly, the chemical nature and amounts of the oxidized lipids that are provided to experimental animals. Despite the known implications of oxidized lipids in a number of degenerative and chronic diseases, the real contribution of those incorporated through the diet is at present unknown. It is not known whether their concentrations are sufficient to cause detrimental nutritional effects [11].

Isolation and structural determination of the main oxidation products of the common dietary unsaturated fatty acids were well established using model lipid systems at the end of the 70's [12]. Complex analytical methods mainly based on the combination of liquid chromatography and mass spectrometry have been reported for the identification of oxidation compounds in a variety of samples, principally those of biological nature [13-15]. Recently, chromatography methods for the analyses of primary [16] and secondary [17] oxidation products of triacylglycerols (TAG) have been reviewed. On the other hand, studies dealing with quantitative analysis of oxidized lipids in foods are rather scarce. The principal limitations of the quantitative determination are due to a large number of compounds formed from 
numerous TAG, their low contents as individual species and their relatively low stability. Quantitative analytical studies have been concentrated on specific compounds found in biological samples [13]. Because of their potential toxicity, glycerolipid aldehydes, also known as core aldehydes, and small aldehydes such as acrolein, malodialdehyde and hydroxyalquenals have been the most studied $[13,18]$. The analytical approaches based on HPLC-MS used in most of these studies have not been adopted up to now. This is because of the relatively elevated cost of the equipment and the expense involved in its operation and maintenance.

In a previous study we proposed a simple method of quantitative analysis for the main oxidation products of linoleic acid in oils, i.e. hydroperoxy-, keto- and hydroxy-dienes. This is based on a derivatization step to convert the TAG molecules into fatty acid methyl esters (FAME) that are analyzed by normal-phase HPLC-UV [19]. The derivatization step caused changes in the composition of the compounds analyzed, as slight losses of hydroperoxydienes and formation of keto- and hydroxy-dienes were observed.

The coupling in series of an evaporative light scattering detector to the HPLC-UV method was useful to also determine oleic acid oxidation products in both model lipids [20] and oils [21]. Results obtained in five edible oils containing different contents of oleate, linoleate and linolenate acyl chains, namely, conventional sunflower, high-oleic sunflower, high-stearic high-oleic sunflower, rapeseed and soybean oils, showed that linoleate oxidation products were predominant in all cases. Substantial formation of oleate oxidation compounds was not observed in the monounsaturated oils until the tocopherols naturally present were completely lost, i.e. at advanced global oxidation extent. The analysis of the main oxidation products of linoleate proved to be a good analytical approach to evaluate the global oxidation extent in oils containing oleic and linoleic acids as the only unsaturated fatty acids present at significant 
amounts. For monounsaturated oils with low levels of linoleate, it was concluded that the lower the global oxidation extent, the better was the analytical approach [21].

With the aim of avoiding any derivatization step that may result in analytical artifacts and so modify the composition of analytes, the objective of the present study was to explore the possibilities of the direct analysis by normal-phase HPLC-DAD of the amounts of the main oxidation products of linoleate in intact samples of edible vegetable oils, i.e. as TAG molecules instead of FAME derivatives. In this regard, the direct analysis of main oxidation products by a simple method as is HPLC-DAD, using a common chromatograph easily available in research laboratories, would be of great convenience in oxidation studies and would also contribute to improving the characterization of oxidized oils in nutritional studies. A comparison with the analysis of the FAME derivatives mentioned above, which was validated elsewhere [19], was made to assess its utility. Prior to the analysis of oils, which are constituted by a number of different TAG, trilinolein was first assayed as a simplified lipid system. High-linoleic sunflower oil (HLSO) and high-oleic sunflower oil (HOSO) were the oils studied. A follow-up of oxidation at $40{ }^{\circ} \mathrm{C}$ of the model lipid and the two oils was performed to evaluate samples with different oxidation levels. The samples were characterized by applying the specific extinction at $232 \mathrm{~nm}\left(\mathrm{~K}_{232}\right)$ and the peroxide value. Analysis of polymers by high-performance size-exclusion chromatography (HPSEC) with refractive-index detection was also applied as a rapid control measure to discard samples in advanced oxidation states [22].

\section{Materials and Methods}

\subsection{Chemicals}

Trilinolein (> 99\%) was purchased from Nu-Check-Prep (Elysian, MN, USA) and used as received. Diethyl ether stabilized with $1 \%$ v/v ethanol (Super purity solvent, HPLC grade) 
was acquired from Romil, LTD (Cambridge, UK) and n-heptane (99\% purity, HPLC grade) from Carlo Erba Reactifs-SDS (Val de Reuil, France). Both HPLC solvents were used as received. Any other chemical used was of analytical grade at least.

\subsection{Oil samples}

High-linoleic sunflower oil (HLSO) and high-oleic sunflower oil (HOSO) were supplied by a local refinery (Andújar, Jaén, Spain). The two oils were edible refined oils. The fatty acid compositions were 6.7\% C16:0, 0.2\% C16:1, 3.6\% C18:0, 33.0\% C18:1, 55.2\% C18:2 and 1.3\% others for HLSO, and 4.1\% C16:0, 4.6\% C18:0, 77.6\% C18:1, 11.7\% C18:2 and 2.0\% others for HOSO.

\subsection{Oxidation conditions}

A 10 -g sample of trilinolein was placed in a 250 -mL beaker and oxidized at $40{ }^{\circ} \mathrm{C}$ in the dark in an oven with air circulation. The surface-to-lipid-volume ratio was $2 \mathrm{~cm}^{-1}$. Aliquots were withdrawn periodically and kept at $-25^{\circ} \mathrm{C}$ until analyses.

Samples of $20 \mathrm{~g}$ of the oils were placed in Petri dishes (14.5 cm i.d.) that were left open to the air and oxidized at $40{ }^{\circ} \mathrm{C}$ in the dark in the oven with air circulation. The surface-to-oilvolume ratio was $7 \mathrm{~cm}^{-1}$. An aliquot of each sample was taken in each sampling and kept at $25{ }^{\circ} \mathrm{C}$ until analyses. The samples were oxidized until the tocopherols naturally present were almost or completely depleted.

\subsection{Reduction of samples with $\mathrm{NaBH}_{4}$}

Oxidized samples were selected and reduced with $\mathrm{NaBH}_{4}$ to identify hydroxy- compounds. The procedure followed was the one reported by Hämäläinen et al. [23] with a few modifications. A volume of $6 \mathrm{~mL}$ of a saturated $\mathrm{NaBH}_{4}$ solution in isopropanol $(10 \mathrm{mg} / \mathrm{mL})$ was added to a 200-mg aliquot of an oxidized oil sample. The isopropanol had been previously dried with anhydrous $\mathrm{Na}_{2} \mathrm{SO}_{4}$. The reaction mixture was stirred at room 
113 temperature under nitrogen for one hour. The reaction was stopped with $6 \mathrm{~mL}$ water and the

114 excess of the reagent was neutralized with aqueous $\mathrm{HCl}(5 \%$, w/w). Saturated aqueous solution of $\mathrm{NaCl}(5 \mathrm{~mL})$ was added and the lipids transformed were extracted using one extraction with diethyl ether $(10 \mathrm{~mL})$. The organic phase was washed with $10 \mathrm{~mL}$ water, dried over anhydrous $\mathrm{Na}_{2} \mathrm{SO}_{4}$ and filtered with paper filter. The solvent was first evaporated in a rotary evaporator at $40^{\circ} \mathrm{C}$ and then taken to dryness with a stream of nitrogen.

\subsection{Direct HPLC analysis}

\subsubsection{Chromatographic conditions}

The trilinolein and the oil samples were dissolved in n-heptane at a concentration of 1-50 $\mathrm{mg} / \mathrm{mL}$ and directly analyzed in an Agilent 1260 Infinity HPLC chromatograph (Agilent Technologies, USA). The chromatograph was equipped with a 1260 quaternary pump VL (G1311C), a 1260 standard autosampler (G1329B), a 1260 thermostatted column compartment (TCC) (G1316A) and a 1260 diode array detector (DAD) VL (G1315D) with a standard measure cell (13 $\mu \mathrm{L}$ volume, $10 \mathrm{~mm}$ cell path length). A silica HPLC column (LiChrospher ${ }^{\circledR}$ Si 60, 250 mm x 4 mm i.d., $5 \mu$ m particle size) (Merck, Darmstadt, Germany) was used. The volume of sample analyzed was $20 \mu \mathrm{L}$. The temperature of the TCC was set at $25{ }^{\circ} \mathrm{C}$. The separation of analytes were performed using isocratic elution with nheptane:diethyl ether (82:18, v/v) with a flow rate of $1 \mathrm{~mL} / \mathrm{min}$. Ethanol present in diethyl ether as a stabilizer was not removed. Hydroperoxy- and hydroxy- dienes were evaluated at $234 \mathrm{~nm}$, while ketodienes were at $268 \mathrm{~nm}$.

\subsubsection{Response factors}

Following a previous study [24], quantitative data were obtained by applying the response factors determined for methyl-linoleate oxidation products, i.e. methyl 13-hydroperoxy-(Z)9,(E)-11-octadecadienoate, methyl 13-hydroxy-(Z)-9,(E)-11-octadecadienoate and methyl 13- 
137 keto-(Z)-9,(E)-11-octadecadienoate. The standards were prepared in the lab according to the

138 previous study [24]. Expressed in $\mathrm{nmol}^{-1} \mathrm{~mL}$, the response factors obtained were 38.3( \pm 0.3$)$

139 and 40.6 $( \pm 0.2)$ for hydroperoxy- and hydroxy-dienes, respectively, at $234 \mathrm{~nm}$ and 39.2( \pm 0.1$)$

140 for keto-dienes at $268 \mathrm{~nm}$. The response factor for hydroperoxydienes at $268 \mathrm{~nm}$ was found to

141 be $0.172( \pm 0.007) \mathrm{nmol}^{-1} \mathrm{~mL}$.

$142 \quad$ 2.5.3 Linearity

143 Linearity of chromatographic response for hydroperoxy- and hydroxy-dienes was evaluated

144 by starting from the most oxidized sample of trilinolein, i.e. a sample oxidized at $40{ }^{\circ} \mathrm{C}$ for 30

145 h. Different solutions of this sample were prepared by dilution with n-heptane and analyzed

146 by HPLC-DAD. Similarly, linearity for ketodienes was evaluated from the most oxidized

147 sample of HLSO, i.e. a sample that was oxidized at $40^{\circ} \mathrm{C}$ for $35 \mathrm{~d}$. Also, different solutions of

148 this sample prepared by dilution with n-heptane were analyzed.

$149 \quad$ 2.5.4 Sensitivity

150 The limits of detection (LOD) and quantification (LOQ) were estimated for each group of 151 compounds following the signal-to-noise ratio criterion. LOD and LOQ were estimated for a 152 signal-to-noise ratio of 3 and 10, respectively. They were calculated from the noise magnitude 153 that was taken as an estimate of the blank standard deviation [25]. An oil sample 154 concentration of $50 \mathrm{mg} / \mathrm{mL}$ was considered for the determinations of LOD and LOQ.

$155 \quad 2.5 .5$ Precision

156 Repeatability, expressed as coefficient of variation (CV), was determined from six replicates 157 in a series of oil samples oxidized at different oxidation extents.

\subsubsection{Accuracy}

159 Accuracy was estimated for hydroperoxydienes only. A trilinolein sample oxidized at the 160 conditions described above at a low oxidation extent was used to isolate hydroperoxydienes. 
161

162

163

164

165

174 For comparative purposes, the oxidized fatty chains in the trilinolein and oil samples were

The sample presented a level of ketodienes close to their LOQ and hydroxydienes were not detected. Trilinolein hydroperoxides were isolated by silica-packed column chromatography by applying the same procedure as that used for the determination of polar compounds in used frying oils, following IUPAC standard method 2.507 [26]. The isolation of the polar fraction was performed using a simultaneous fractionation of four samples of $2.5 \mathrm{~g}$ oxidized trilinolein each in four columns. The polar fractions were joined to have approximately $40 \mathrm{mg}$ isolated sample. An HPLC direct analysis of the polar fraction showed hydroperoxydienes and ketodienes only. The levels of ketodienes present in the isolated sample were $1.5 \mathrm{~mol} \%$. Therefore, the purity of hydroperoxydienes was estimated to be $98.5 \mathrm{~mol} \%$. The isolated hydroperoxydienes were added to a fresh sample of HLSO at different concentrations, which ranged from 5 to $40 \mathrm{mmol} / \mathrm{kg}$. The samples were analyzed by HPLC and the recovery value was calculated as the mean value of all the determinations.

\subsection{HPLC analysis of derivatized samples}

also analyzed. A derivatization reaction to transform the TAG into FAME was applied according to a previous study [19]. A 200-mg sample was accurately weighed into a screwcapped centrifuge tube $(13 \mathrm{~cm} \times 10 \mathrm{~mm}$ I.D.) and a volume of $3 \mathrm{~mL}$ of methyl tert-butyl ether was added. Then, a 1.5-mL volume of $0.2 \mathrm{M} \mathrm{NaOMe}$ was added, the tube closed, shaken for 1 min, and allowed it to stand for $2 \mathrm{~min}$. The solution was neutralized by adding $0.1 \mathrm{~mL}$ of 0.5 $\mathrm{M} \mathrm{H}_{2} \mathrm{SO}_{4}$ in methanol. Finally, $3 \mathrm{~mL}$ of distilled water was added, shaken for $10 \mathrm{~s}$ and centrifuged at $5000 \mathrm{rpm}$ for $1 \mathrm{~min}$. The organic layer was separated and the solvent was first evaporated in a rotary evaporator at $40{ }^{\circ} \mathrm{C}$ and then taken to dryness with a stream of nitrogen. Solutions of the FAME samples in n-heptane at a concentration of $1-50 \mathrm{mg} / \mathrm{mL}$ were analyzed by HPLC. The chromatograph and the chromatographic conditions were the same as 
185 those described above for the direct analysis of the lipid or oil samples. Also, quantitative data 186 were obtained by applying the response factors outlined above.

187

188

189

190

191

192

193

194

195

196

197

\subsection{Analysis of polymers}

Analysis of TAG polymers was performed by HPSEC with refractive index detection according to IUPAC standard method 2.508 [26].

\subsection{Peroxide value}

Peroxide value was determined by the iodometric assay according to IUPAC standard method 2.501 [26]. Oil samples of $500 \mathrm{mg}$ and $1 \times 10^{-2} \mathrm{M} \mathrm{Na}_{2} \mathrm{~S}_{2} \mathrm{O}_{3}$ solution were used.

\subsection{Ultraviolet light absorption at $232 \mathrm{~nm}\left(K_{232}\right)$}

Specific extinction at $232 \mathrm{~nm}$ was determined in cyclohexane as a measure of total conjugated dienes according to AOCS standard method Ch 5-91 [27].

\subsection{Analysis of tocopherols}

Analysis of tocopherols was carried out by normal-phase HPLC with fluorescence detection following IUPAC standard method 2.411 [26].

\subsection{Statistical analysis}

The trilinolein and oil samples were analyzed by HPLC in triplicate to determine lipid oxidation products and results were expressed as mean values followed by the standard deviation. As to the other analytical determinations applied for chemical characterization, the samples were analyzed in duplicate and results were expressed as mean values. Comparisons of means were performed by the Student's $t$ test. Comparisons between the TAG and FAME analyses were performed by applying a mixed model analysis of repeated measurements, i.e. those for the analytical method and the three analytical replications, using the oxidation time and the type of analytical method as fixed factors. This analysis was performed separately for 
each type of lipid sample, namely, trilinolein, HLSO and HOSO. For practical purposes, the

209 HOSO sample showing the most advanced oxidation extent (82 days) was not considered in 210 the statistical analysis. Linear regression analysis was applied between the concentrations of 211 hydroperoxydienes determined by the TAG analysis and those by the FAME analysis to 212 establish relationships between both parameters. Similarly, the total amounts of the 213 compounds determined by the two analytical methods received the same statistical treatment. 214 The 24.0 SPSS Statistics program was used (SPSS Inc., Chicago, IL, USA). Significance was defined at $p<0.05$.

\section{Results and Discussion}

\subsection{Chromatographic conditions}

The chromatographic conditions applied in the direct analysis of oils were the same as those employed in the analysis of FAME derivatives, previously reported [19]. It was not necessary to change the conditions because the results obtained were satisfactory. Thus, on a silica HPLC column, the isocratic regime conditions employed using a blend of n-heptane:diethyl ether 82:18 (v/v) enabled the elution of the analytes in a reasonable time. Oxidized samples of trilinolein showed chromatograms that were not complex because of the specificity of the detection of conjugated diene structures (Fig. 1). Hydroperoxydienes were grouped in a 225 similar way to the analysis of the FAME derivatives [19], but at shorter retention times due to 226 a lower polarity. Eight different hydroperoxide isomers would be expected in trilinolein, the four stereoisomers of linoleate, i.e. cis,trans- and trans,trans-9- and 13-isomers, located on

228 the 1(3)- or 2-positions of the TAG molecule [28]. The chromatographic conditions applied in 229 the present study did not allow for the separation between the eight isomers, although the 230 number of unresolved peaks observed on the band was eight. As oxidation progressed, a band 231 formed by a number of different chromatographic peaks of low intensity was also observed at retention times much longer than those of hydroperoxydienes (Fig. 1A). Because of its 
similarity to the FAME analysis (Fig. 1B), such a chromatographic band was first assigned to

234 hydroxydienes, although more complex oxidation compounds could not be ruled out, as it will

235 be dealt later. Ketodienes were also grouped at the chromatographic conditions applied.

236 Unlike the FAME analysis, they were not completely separated from hydroperoxydienes.

237 However, the overlapping between both bands was small and so the measure of the ketodiene

238 area was not significantly affected (Fig. 1a-b).

239 Despite the number of different TAG present in oils, the chromatograms of the oxidized oils 240 were not very different from those of oxidized trilinolein, as shown in Fig. 2A for HLSO.

241 Hydroperoxydienes were grouped in a band of unresolved chromatographic peaks. Similarly, 242 a band of peaks of low intensity was also observed in the hydroxy- region of the 243 chromatograms as oxidation progressed. Unlike the trilinolein, the ketodienes presented a 244 wider band with clear overlapping with that of hydroperoxydienes as a consequence of a 245 greater number of keto- and hydroperoxy-diene TAG in oils (Fig. 2B). Also, it was found that 246 the greater the oxidation extent, the more was affected the band of keto- by that of 247 hydroperoxy-dienes. In contrast, the band of hydroperoxydienes was unaffected by that of 248 ketodienes due to the comparatively low levels of the latter and their low light absorption at $249234 \mathrm{~nm}$.

250 With the aim of identifying compounds in the hydroxy- region different oil samples were 251 reduced with $\mathrm{NaBH}_{4}$. All the hydroperoxydienes were practically transformed into their 252 parent hydroxydienes and were displaced to the hydroxy- region, as shown in Fig. 2C for 253 HLSO. The relative intensities of the unresolved peaks suggested that the first part of the band 254 corresponded to the transformed mono-hydroperoxides. The second part could be due to TAG 255 with more than one hydroxy function, probably formed from bis- and tris-hydroperoxydienes 256 [28-31]. It can also be observed that the peaks at longer retention times disappeared with the $257 \mathrm{NaBH}_{4}$ reduction, suggesting the presence of compounds of greater structural complexity. 


\subsection{Validation of the analytical method}

The validation of the direct analysis of oils was mainly based on that carried out for the analysis of the FAME derivatives proposed in a previous publication [19]. Quantitation was performed by applying the HPLC response factors determined for synthesized FAME compounds that represent each group of the compounds of interest. These were assumed to have the same response factors as when forming part of TAG molecules. In fact, intact and derivatized samples of oxidized trilinolein presented chromatographic responses for hydroperoxydienes whose areas under the curve showed similar values, which indicated that the chromophore remained unchanged when the TAG were transformed into the FAME derivatives. Similarly, the same was assumed for hydroxy- and keto-dienes. Therefore, quantitative data were obtained assuming the same response factors as those used in the FAME analysis, but obviously considering a molar basis.

\subsubsection{Linearity}

Hydroperoxydienes exhibited an HPLC-DAD response that was linear in the range of concentrations tested, i.e. from 3 to $4000 \mu \mathrm{M}$. Similar results were obtained for methyl 13hydroperoxy-(Z)-9,(E)-11-octadecadienoate synthesized in the lab and used in the validation of the analysis of the FAME derivatives [24]. The band assigned to hydroxydienes and that of ketodienes also presented linearity in all the range of concentrations assayed, i.e. from 50 to $500 \mu \mathrm{M}$ and from 5 to $50 \mu \mathrm{M}$, respectively. Linear regression coefficients were higher or equal to 0.999 in the three cases (not presented).

\subsubsection{Sensitivity}

The HPLC-DAD analysis presented elevated sensitivity for the three groups of compounds, especially for hydroperoxy- and keto-dienes. The determination of hydroxydienes was obviously less sensitive because of the greater width of the chromatographic band. The 
estimated LOD values were $0.03 \mathrm{mmol} / \mathrm{kg}$ oil for hydroperoxy- and keto-dienes and 0.22 $\mathrm{mmol} / \mathrm{kg}$ oil for hydroxydienes, whereas the LOQ values were $0.06 \mathrm{mmol} / \mathrm{kg}$ oil for hydroperoxy- and keto-dienes and $0.75 \mathrm{mmol} / \mathrm{kg}$ oil for hydroxydienes.

\subsubsection{Precision}

The CVs were found to be $\leq 5 \%$ for hydroperoxydienes and $\leq 7 \%$ for both keto- and hydroxydienes, whereas such figures were reported to be respectively $\leq 6 \%$ and $\leq 15 \%$ in the FAME analysis [19].

\subsubsection{Accuracy}

Accuracy was estimated by assays of recovery of isolated hydroperoxydienes added to a fresh sample of HLSO. The recovery value found was $99( \pm 1) \%$.

\subsection{Quantitative determination of oxidation compounds in trilinolein samples}

Formation of hydroperoxy-, keto- and hydroxy-dienes was studied in trilinolein and the direct analysis was compared to the analysis of FAME derivatives. The results obtained are listed in

\section{Table 1.}

The results of hydroperoxydienes were quite similar to those of the FAME analysis, although, as expected [19], slightly higher concentrations were obtained as oxidation progressed. A linear regression analysis between both measures indicated that the FAME concentrations were on average approximately $94 \%$ of the TAG results $\left([\mathrm{OOH}]_{\mathrm{FAME}}=0.938( \pm 0.009)\right.$ $\left.[\mathrm{OOH}]_{\mathrm{TAG}}, \mathrm{r}^{2}=0.9996\right)$. As outlined above, such analytical differences were close to the precisions of both methods and so to the experimental analytical error. In addition, such differences suggested losses of approximately 6 molar\% for hydroperoxydienes in the derivatization reaction, which supports the results found in a previous study in which the transmethylation reaction was applied to oxidized FAME samples to assess chemical transformations [19]. 
The concentrations of ketodienes were significantly lower in the TAG analysis, which was expected because of the formation of ketodienes in the derivatization reaction in the FAME analysis [19]. However, the concentrations found in the latter were significantly greater than those expected from the results obtained in a previous study, in which it was observed that not more than $2.1 \mathrm{wt} \%$ of hydroperoxydienes were transformed into keto- and hydroxy-dienes as a whole when the transmethylation conditions were applied to oxidized FAME samples [19].

312 In contrast, the results in the present study suggested that $10-11$ molar\% of simple hydroperoxydienes were transformed into simple ketodienes. This is not consistent with the fact that the results for simple hydroperoxydienes suggested losses of as low as 6 molar\% on average as a consequence of the derivatization reaction. Consequently, the direct analysis of 316 the oil samples pointed out that the determination of ketodienes in the FAME analysis 317 requires further research, which is out of the scope of the present study.

The concentrations of the group of compounds determined as hydroxydienes in the TAG analysis were substantially greater compared to the FAME analysis. This was clearly indicative of the coelution of compounds other than simple or mono-hydroxydienes. TAG

321 holding more than one oxidized acyl chain could have been involved [28-31]. According to 322 studies by Neff et al. [28], formation of bis- and tris-hydroperoxides, i.e. TAG with two and 323 three acyl chains holding the hydroperoxy function, were found in trilinolein oxidized at 40 $324{ }^{\circ} \mathrm{C}$ from peroxide values (PVs) as low as $18 \mathrm{meq} / \mathrm{kg}$. Although quantitative data were not 325 unfortunately provided, the relative area percentage in reverse-phase HPLC chromatograms 326 indicated that the relative proportions of mono-, bis- and tris-hydroperoxydienes were 327 approximately 69, 21 and 10\%, respectively, at PV 125 meq/kg. Therefore formation of 328 compounds with more than one hydroperoxy group seems not to be negligible during 329 autoxidation of trilinolein. Such compounds are obviously of higher polarity than their parent 330 mono-hydroperoxides and could elute in the hydroxy- region of the chromatogram. In 

addition, their derivatization to FAME would enable the grouping of compounds in the FAME analysis and so it could be explained the fact that the HPLC chromatograms of the FAME derivatives were not complex in terms of appearance of unidentified chromatographic peaks (Fig. 1B). Also, bis- and tris-hydroperoxides could also contribute to the relatively high concentrations of ketodienes found in the FAME analysis.

It is of interest to emphasize that bis- and tris-hydroperoxydienes would have respectively response factors twice and three times greater than that of the mono-hydroperoxides, expressed on a molar basis. Therefore, the method proposed in the present study allows for determining the molar concentrations of oxidized acyl chains on TAGs, which correspond to the same molar concentrations of TAG for mono- hydroperoxy, keto and hydroxy compounds.

The total amounts of oxidation compounds determined by the direct analysis of oxidized trilinolein were similar to those of the FAME analysis, although slightly higher as shown by the statistical analysis (Table 1). A linear regression analysis between both measures exhibited that the total concentrations of the oxidation compounds evaluated in the FAME analysis were on average approximately $95 \%$ of the TAG results $\left([\text { Total }]_{\mathrm{FAME}}=\right.$ $\left.0.949( \pm 0.007)[\text { Total }]_{\mathrm{TAG}}, \mathrm{r}^{2}=0.9998\right)$. In addition, the results found in the TAG analysis showed that the mono-hydroperoxides evaluated constituted more than 90 molar\% of the compounds quantified when polymerization was not yet significant.

\subsection{Quantitative determination of oxidation compounds in oil samples}

Quantitative results found in oxidized HLSO and HOSO samples are listed in Tables 2-3. For comparative purposes, the chromatographic band formerly assigned to hydroxydienes was divided into two parts, the one formed by mono- and other hydroxydienes and the band due to compounds of greater structural complexity (Fig. 2A). Because of their polarity, TAG with 
more than one hydroperoxy function should not be discarded in the hydroxy region, as the results obtained in the trilinolein samples suggested. Also, the concentrations of ketodienes were determined by difference from the total area of the band formed by keto- and hydroperoxy-dienes at $268 \mathrm{~nm}$ (Fig. 2B). The area of hydroperoxydienes at $268 \mathrm{~nm}$ was estimated from their concentration values determined at $234 \mathrm{~nm}$ and their response factor at that wavelength, which was approximately two hundred times lower than that at $234 \mathrm{~nm}$.

As observed in the trilinolein samples, the amounts of hydroperoxydienes determined in the two oils by the TAG analysis were similar to those found in the FAME analysis. Although slightly higher concentrations were found for the former in a few samples, a global statistical analysis of the data obtained for each type of oil separately showed no significant differences between the two methods. This was supported by the fact that the differences found between the two methods in the trilinolein samples were close to the experimental analytical error. In addition, the results of the FAME analysis were similar to those found in previous studies, in which they were expressed on a weight basis [19,21].

In the vicinity of the end of the induction period, defined as the time at which the oil becomes unprotected by the total loss of the naturally occurring antioxidants (tocopherol) [32], the amounts of hydroperoxydienes were found to be 78 and $32 \mathrm{mmol} / \mathrm{kg}$ in the HLSO and HOSO, respectively. It has been found in previous studies that hydroperoxydienes constitute by far the most abundant compounds formed in common vegetable oils containing linoleate and oleate as the only oxidizable substrates present at significant amounts [19,21]. Oxidation of oleate seems to be efficiently inhibited in the presence of substantial amounts of the tocopherols naturally present in oils, i.e. at low global oxidation extents [33]. Even in monounsaturated oils in which the levels of linoleate are relatively low, such as the HOSO tested in the present study, the oxidation of oleate was not relatively significant until the PV was higher than $50 \mathrm{meq} / \mathrm{kg}[19,21]$. Therefore, the quantification of the main oxidation 
products of linoleate seems to be a good analytical approach to evaluate the global oxidation extent in this kind of oils. For monounsaturated oils containing low levels of linoleate, the lower the oxidation extent, the better will be this analytical approach. Against analytical indices, such as the PV and $\mathrm{K}_{232}$, the measure of hydroperoxydienes is not subjected to possible analytical interferences that may occur especially when food lipid extracts are analyzed. Such interferences are normally due to food components other than hydroperoxides that are extracted along with the lipids and have a response in the test [34].

The estimated amounts of ketodienes in the direct analysis were significantly lower compared to the FAME analysis. In addition, the levels of ketodienes in the FAME analysis were similar to those found in previous studies, but higher than expected [19], as also observed in the model lipid system. While the amounts of ketodienes found by the TAG analysis at the end of the induction periods were respectively 1.0 and $0.82 \mathrm{mmol} / \mathrm{kg}$ in HLSO and HOSO, these 392 figures were found to be 5.1 and $2.58 \mathrm{mmol} / \mathrm{kg}$, respectively, in the FAME analysis. The 393 results obtained in both oils suggested that approximately 5 molar\% of monohydroperoxydienes on average were transformed into ketodienes in the derivatization step of 395 the FAME analysis. Therefore, the amounts of ketodienes found by the TAG analysis were 396 more reliable and realistic than those determined in the FAME analysis.

397 The compounds analyzed as hydroxy- in the TAG analysis were detected at concentrations 398 that were below the LOQ in the fresh samples and the samples with low oxidation (Tables 2399 3). Substantial formation was not observed until the PV was higher than $90 \mathrm{meq} / \mathrm{kg}$ oil in the 400 HLSO and $80 \mathrm{meq} / \mathrm{kg}$ oil in the HOSO. The concentrations of hydroxy- compounds were 401 similar between the two methods, although obviously significantly greater levels were 402 obtained with the FAME analysis as oxidation progressed as a result of hydroperoxydiene 403 transformations. Also, the concentrations of hydroxydienes found in the FAME analysis were 
404 similar to those found in previous studies, in which they were expressed on a weight basis $405[19,21]$.

406 Concerning the group determined as other compounds, it was observed an increase that was in 407 parallel to the formation of hydroxy- compounds. When the HOSO became unprotected by 408 the total loss of tocopherols, their concentrations substantially increased along with the 409 polymerization compounds. However, whether these correspond to, for example TAG dimers, 410 is a subject that would require further research. If so and the TAG were linked between each 411 other by a peroxide bridge, this would explain the fact that they disappeared with the $\mathrm{NaBH}_{4}$ 412 reduction. Consequently, they would contribute to the band of hydroxy- compounds in 413 reduced samples.

414 The analytical method proposed in the present study can be applied using common high415 performance liquid chromatographs. It would be necessary for it to determine the response 416 factors from the standards synthesized in the lab as FAME, as described elsewhere [19,24]. 417 Alternatively, an estimate of the response factors could be obtained from methyl linoleate 418 oxidized at PVs not higher than $100 \mathrm{meq} / \mathrm{kg}$. Determining the PV in such samples, the 419 concentrations of hydroperoxydienes can be estimated from the curve that experimentally 420 relates both parameters $([\mathrm{LOOH}](\mathrm{mmol} / \mathrm{kg})=0.365( \pm 0.012) \mathrm{PV}(\mathrm{meq} / \mathrm{kg}), \mathrm{r}=0.998)$, 421 obtained from pure methyl linoleate hydroperoxides in a previous report [24].

\section{4. Conclusions}

423 The HPLC-DAD method proposed enables to determine the concentrations of mono424 hydroperoxydienes in edible oils without applying any isolation or derivatization step. It is 425 therefore direct, rapid and sensitive, showing values of 0.03 and $0.06 \mathrm{mmol} / \mathrm{kg}$ oil for LOD 426 and LOQ, respectively. The results have shown that it is precise ( $\mathrm{CV} \leq 5 \%)$ and also more 427 accurate when compared to the FAME analysis, which involves chemical transformations. 
428 The method also enables the determination of the minor levels of ketodienes. As intact TAG 429 molecules are measured, the results are more reliable than those provided by the FAME 430 analysis, in which ketodienes are formed in part in the derivatization step. In contrast, the 431 analysis of TAG hydroxydienes is not as simple as that of the FAME analysis. A wide 432 chromatographic band is formed by TAG hydroxydienes and a number of minor compounds 433 with more structural complexity, probably including TAG with more than one oxidized chain 434 and different functional groups. Nevertheless, such a band is indicative of the progress of 435 oxidation and so it could be useful for qualitative purposes.

436 Lastly, using common HPLC devices, the method proposed can be applied to determine the 437 amounts of the more abundant oxidized lipids in a variety of oils and food lipids, to estimate 438 the oxidation extent, and in kinetic and other oxidation studies.

439 Acknowledgements

440 This work was funded by the Spanish Ministry of Economy and Competitiveness through 441 project AGL2013-45110-R. 


\section{References}

443

444

445

446

447

448

449

450

451

452

453

454

455

456

457

458

459

460

461

462

463

464

465

466

467

468

469

470

[1] S. Gargiulo, G. Testa, P. Gamba, E. Staurenghi, G. Poli, G. Leonarduzzi, Oxysterols and 4-hydroxy-2-nonenal contribute to atherosclerotic plaque destabilization, Free Radic. Biol. Med. 111 (2017) 140-150.

[2] S.A. Vieira, G. Zhang, E.A. Decker, Biological implications of lipid oxidation products, J. Am. Oil Chem. Soc. 94 (2017) 1-13.

[3] K. Zarkovic, A. Jakovcevic, N. Zarkovic, Contribution of the HNEimmunohistochemistry to modern pathological concepts of major human diseases, Free Radic. Biol. Med. 111 (2017) 110-126.

[4] T.S. Anthonymuthu, N. Kim-Campbell, H. Bayir, Oxidative lipidomics: applications in critical care, Curr. Opin. Crit. Care 23 (2017) 251-256.

[5] J.H. Lu, B.X. Chen, T.T. Chen, S.Y. Guo, X.L. Xue, Q. Chen, M.M. Zhao, L. Xia, Z.J. Zhu, L.M. Zheng, H.Y. Yin, Comprehensive metabolomics identified lipid peroxidation as a prominent feature in human plasma of patients with coronary heart diseases, Redox Biol. 12 (2017) 899-907.

[6] A. Catalá, M. Díaz, Impact of lipid peroxidation on the physiology and pathophysiology of cell membranes, Front. Physiol. 7 (2016) 423.

[7] A.O. Falade, G. Oboh, A.I. Okoh, Potential health implications of the consumption of thermally-oxidized cooking oils-a review, Pol. J. Food Nutr. Sci. 67(2) (2017) 95-106.

[8] A. Zeb, S.U. Rahman, Protective effects of dietary glycine and glutamic acid toward the toxic effects of oxidized mustard oil in rabbits, Food Funct. 8(1) (2017) 429-436.

[9] A. Zeb, I. Haq, The protective role of tomato powder in the toxicity, fatty infiltration and necrosis induced by oxidized tallow in rabbits, J. Food Biochem. 40 (2016) 428-435.

[10] J. Kanner, Dietary advanced lipid oxidation endproducts are risk factors to human health, Mol. Nutr. Food Res. 51 (2007) 1094-1101.

[11] M.C. Dobarganes, G. Márquez Ruiz, Oxidized fats in foods, Curr. Opin. Clin. Nutr. Metab. Care 6 (2003) 157-163.

[12] E.G. Hammond, P.J. White, A brief history of lipid oxidation, J. Am. Oil Chem. Soc. 88 (2011) 891-897. 
[13] A. Kuksis, O. Sjovall, LC/MS and lipid oxidation, in: M.M. Mossoba, J.K.G. Kramer, J.T. Brenna, R.E. McDonald (Eds.), Lipid Analysis and Lipidomics-New Techniques and Applications, AOCS Press, Illinois, 2006, pp. 109-156.

[14] A. Kuksis, J.P. Suomela, M. Tarvainen, H. Kallio, Lipidomic analysis of glycerolipid and cholesteryl ester autooxidation products, Mol. Biotechnol. 42(2) (2009) 224-268.

[15] A. Reis, Oxidative phospholipidomics in health and disease: achievements, challenges and hopes, Free Radic. Biol. Med. 111 (2017) 25-37.

[16] A. Zeb, Chemistry and liquid chromatography methods for the analyses of primary oxidation products of triacylglycerols, Free Rad. Res. 49 (2015) 549-564.

[17] W. Xia, S.M. Budge, Techniques for the analysis of minor lipid oxidation products derived from triacylglycerols: epoxides, alcohols, and ketones, Compr. Rev. Food. Sci. Food Saf. 16 (2017) 735-758.

[18] B.C. Sousa, A.R. Pitt, C.M. Spickett, Chemistry and analysis of HNE and other prominent carbonyl-containing lipid oxidation compounds, Free Radic. Biol. Med. 111 (2017) 294-308.

[19] A. Morales, S. Marmesat, C. Dobarganes, G. Márquez-Ruiz, J. Velasco, Quantitative analysis of hydroperoxy-, keto- and hydroxy-dienes in refined vegetable oils, J. Chromatogr. A 1229 (2012) 190-197.

[20] A. Morales, S. Marmesat, C. Dobarganes, G. Márquez-Ruiz, J. Velasco, Evaporative light scattering detector in normal-phase high-performance liquid chromatography determination of FAME oxidation products, J. Chromatogr. A 1254 (2012) 62-70.

[21] A. Morales, S. Marmesat, M.V. Ruiz-Méndez, G. Márquez-Ruiz, J. Velasco, Formation of oxidation products in edible vegetable oils analyzed as FAME derivatives by HPLCUV-ELSD, Food Res. Int. 62 (2014) 1080-1086.

[22] G. Márquez-Ruiz, M. Martín-Polvillo, M.C. Dobarganes, Quantitation of oxidized triglyceride monomers and dimers as a useful measurement for early and advanced stages of oxidation, Grasas y Aceites 47 (1996) 48-53.

[23] T.I. Hämäläinen, S. Sundberg, M. Mäkinen, S. Kaltia, T. Hase, A. Hopia, Hydroperoxide formation during autoxidation of conjugated linoleic acid methyl ester, Eur. J. Lipid Sci. Technol. 103 (2001) 588-593. 
[24] A. Morales, C. Dobarganes, G. Márquez-Ruiz, J. Velasco, Quantitation of hydroperoxy-, keto- and hydroxy-dienes during oxidation of FAMEs from high-linoleic and high-oleic sunflower oils, J. Am. Oil Chem. Soc. 87 (2010) 1271-1279.

[25] J. Vial, A. Jardy, Experimental comparison of the different approaches to estimate LOD and LOQ of an HPLC method, Anal. Chem. 71 (1999) 2672-2677.

[26] International Union of Pure and Applied Chemistry, Standard methods for the analysis of oils, fats and derivatives, seventh ed., Blackwell Scientific Publications, Oxford, 1992.

[27] Standard Method Ch 5-91, in: AOCS Official methods and recommended practices of the American Oil Chemists’ Society, fifth ed., AOCS Press, Champaign, 1998.

[28] W.E. Neff, E.N. Frankel, K. Miyashita, Autoxidation of polyunsaturated triacylglycerols. I. Trilinoleoylglycerol, Lipids 25 (1990) 33-39.

[29] W.E. Neff, W.C. Byrdwell, Characterization of model triacylglycerol (triolein, trilinolein and trilinolenin) autoxidation products via high-performance liquid chromatography coupled with atmospheric pressure chemical ionization mass spectrometry, J. Chromatogr. A 818 (1998) 169-186.

[30] O. Sjovall, A. Kuksis, H. Kallio, Reversed-phase high-performance liquid chromatographic separation of tert-butyl hydroperoxide oxidation products of unsaturated triacylglycerols, J. Chromatogr. A 906 (2001) 119-132.

[31] A. Zeb, M. Murkovic, Characterization of the effects of $\beta$-carotene on the thermal oxidation of triacylglycerols using HPLC-ESI-MS, Eur. J. Lipid Sci. Technol. 112 (2010) 1218-1228.

[32] G. Márquez-Ruiz, M.C. Dobarganes, Analysis of non-volatile lipid oxidation compounds by high-performance size-exclusion chromatography, in: A. Kamal-Eldin, J. Pokorny (Eds.), Analysis of Lipid Oxidation, AOCS Press, Illinois, 2005, pp. 40-69.

[33] A. Morales, C. Dobarganes, G. Márquez-Ruiz, J. Velasco, Formation of hydroperoxy-, keto- and hydroxy-dienes in FAME from oils: influence of temperature and addition of $\alpha$-tocopherol, J. Am. Oil Chem. Soc. 89 (2012) 675-684.

[34] J. Velasco, S. Marmesat, F. Holgado, G. Márquez-Ruiz, C. Dobarganes, Influence of two lipid extraction procedures on the peroxide value in powdered infant formulas, Eur. Food Res. Technol. 226 (2008) 1159-1166. 


\section{$532 \quad$ Figure captions}

533 Fig. 1. HPLC chromatograms of trilinolein oxidized at $40{ }^{\circ} \mathrm{C}$ for $30 \mathrm{~h}$. Intact sample recorded

534 at $234 \mathrm{~nm}$ (A) and $268 \mathrm{~nm}$ (a). Sample derivatized to FAME recorded at $234 \mathrm{~nm}$ (B) and 268 $535 \mathrm{~nm}(\mathbf{b})$.

536 Fig. 2. HPLC chromatograms of high-linoleic sunflower oil oxidized at $40{ }^{\circ} \mathrm{C}$ for 21 days.

537 Intact sample recorded at $234 \mathrm{~nm}(\mathbf{A})$ and $268 \mathrm{~nm}(\mathbf{B})$. Sample reduced with $\mathrm{NaBH}_{4}$, recorded 538 at $234 \mathrm{~nm}(\mathbf{B})$. 
Table 1 Analyses of trilinolein oxidized at $40^{\circ} \mathrm{C}$ in the dark.

\begin{tabular}{|c|c|c|c|c|c|c|c|c|c|c|}
\hline \multirow{2}{*}{$\begin{array}{l}\text { Time } \\
\text { (h) }\end{array}$} & \multirow{2}{*}{$\begin{array}{l}\text { Pol } \\
\text { (\%) }\end{array}$} & \multirow[b]{2}{*}{$\mathbf{K}_{232}$} & \multicolumn{4}{|c|}{ TAG analysis } & \multicolumn{4}{|c|}{ FAME analysis } \\
\hline & & & $\begin{array}{l}\text { Hydroperoxy- } \\
\text { (mmol/kg) }\end{array}$ & $\begin{array}{c}\text { Keto- } \\
(\mathbf{m m o l} / \mathbf{k g})\end{array}$ & $\begin{array}{l}\text { Hydroxy-* } \\
\text { (mmol/kg) }\end{array}$ & $\begin{array}{c}\text { Total } \\
(\mathrm{mmol} / \mathrm{kg})\end{array}$ & $\begin{array}{c}\text { Hydroperoxy- } \\
\text { (mmol/kg) }\end{array}$ & $\begin{array}{c}\text { Keto- } \\
(\mathbf{m m o l} / \mathbf{k g})\end{array}$ & $\begin{array}{l}\text { Hydroxy- } \\
\text { (mmol/kg) }\end{array}$ & $\begin{array}{c}\text { Total } \\
(\mathbf{m m o l} / \mathbf{k g})\end{array}$ \\
\hline 0 & 0.1 & 3.39 & $0.97 \pm 0.02 \mathrm{a}$ & $0.065 \pm 0.004 b$ & ND & $1.04 \pm 0.05 \mathrm{a}$ & $0.90 \pm 0.05 a$ & $0.15 \pm 0.02 a$ & $<0.16$ & $1.05 \pm 0.07 a$ \\
\hline 5 & 0.1 & 3.40 & $4.13 \pm 0.13 a$ & $0.068 \pm 0.004 b$ & $<0.75$ & $4.20 \pm 0.14 \mathrm{a}$ & $4.01 \pm 0.13 \mathrm{a}$ & $0.47 \pm 0.02 \mathrm{a}$ & $<0.16$ & $4.48 \pm 0.16 a$ \\
\hline 10 & 0.1 & 3.96 & $8.08 \pm 0.03 a$ & $0.064 \pm 0.004 b$ & $0.89 \pm 0.06$ & $9.04 \pm 0.09 a$ & $7.53 \pm 0.26 b$ & $0.94 \pm 0.03 a$ & $<0.16$ & $8.47 \pm 0.30 \mathrm{~b}$ \\
\hline 15 & 0.1 & 5.78 & $15.28 \pm 0.20 \mathrm{a}$ & $0.063 \pm 0.004 b$ & $1.47 \pm 0.01 \mathrm{a}$ & $16.81 \pm 0.21 \mathrm{a}$ & $13.82 \pm 0.43 b$ & $1.71 \pm 0.12 \mathrm{a}$ & $0.16 \pm 0.03 \mathrm{~b}$ & $15.69 \pm 0.57 b$ \\
\hline 20 & 0.1 & 9.52 & $28.13 \pm 0.79 a$ & $0.074 \pm 0.002 b$ & $3.12 \pm 0.13 a$ & $31.33 \pm 0.93 a$ & $25.56 \pm 0.76 b$ & $3.29 \pm 0.13 a$ & $0.34 \pm 0.03 \mathrm{~b}$ & $29.18 \pm 0.92 b$ \\
\hline 25 & 0.2 & 15.87 & $49.53 \pm 0.11 \mathrm{a}$ & $0.085 \pm 0.002 b$ & $5.70 \pm 0.10 \mathrm{a}$ & $55.31 \pm 0.02 \mathrm{a}$ & $47.39 \pm 0.71 b$ & $5.28 \pm 0.43 a$ & $0.74 \pm 0.00 \mathrm{~b}$ & $53.41 \pm 1.14 b$ \\
\hline 30 & 0.5 & 25.49 & $79.61 \pm 1.61 \mathrm{a}$ & $0.119 \pm 0.004 b$ & $11.41 \pm 0.30 \mathrm{a}$ & $91.14 \pm 1.92 \mathrm{a}$ & $74.20 \pm 1.93 b$ & $9.24 \pm 0.31 \mathrm{a}$ & $1.48 \pm 0.06 \mathrm{~b}$ & $86.39 \pm 2.82 b$ \\
\hline
\end{tabular}

Pol, polymers; $\mathrm{K}_{232}$, specific extinction at $232 \mathrm{~nm}$. *Group of compounds formed by simple hydroxydienes and other TAG with similar or higher polarity. ND, not detected. Different letters in the concentrations of each group of compounds for a given sample denote significant differences between the TAG and FAME analyses $(\mathrm{p}<0.05)$. 
Table 2 Analyses of high linoleic sunflower oil oxidized at $40^{\circ} \mathrm{C}$ in the dark.

\begin{tabular}{|c|c|c|c|c|c|c|c|c|c|c|c|}
\hline \multirow[b]{2}{*}{$\begin{array}{l}\text { Time } \\
\text { (days) }\end{array}$} & \multirow[b]{2}{*}{$\begin{array}{c}\text { Toc } \\
(\mathbf{p p m})\end{array}$} & \multirow[b]{2}{*}{$\begin{array}{l}\text { Pol } \\
(\%)\end{array}$} & \multirow[b]{2}{*}{$\begin{array}{c}\text { PV } \\
\text { (meq/kg) }\end{array}$} & \multirow[b]{2}{*}{$\mathbf{K}_{232}$} & \multicolumn{4}{|c|}{ TAG analysis } & \multicolumn{3}{|c|}{ FAME analysis } \\
\hline & & & & & $\begin{array}{c}\text { Hydroperoxy- } \\
\text { (mmol/kg) }\end{array}$ & $\begin{array}{c}\text { Keto- } \\
(\mathrm{mmol} / \mathrm{kg})\end{array}$ & $\begin{array}{l}\text { Hydroxy-* } \\
\text { (mmol/kg) }\end{array}$ & $\begin{array}{c}\text { Others } \\
\text { (mmol/kg) }\end{array}$ & $\begin{array}{c}\text { Hydroperoxy- } \\
\text { (mmol/kg) }\end{array}$ & $\begin{array}{c}\text { Keto- } \\
(\mathrm{mmol} / \mathrm{kg})\end{array}$ & $\begin{array}{l}\text { Hydroxy- } \\
\text { (mmol/kg) }\end{array}$ \\
\hline 0 & 614 & 0.6 & 1.7 & 2.8 & $<0.06$ & $0.381 \pm 0.007 a$ & $<0.75$ & ND & $0.24 \pm 0.02$ & $0.34 \pm 0.02 b$ & $1.15 \pm 0.07$ \\
\hline 7 & 611 & 0.6 & 30.7 & 6.3 & $11.55 \pm 0.27 \mathrm{a}$ & $0.408 \pm 0.001 b$ & $<0.75$ & ND & $9.89 \pm 0.06 b$ & $1.05 \pm 0.03 \mathrm{a}$ & $1.48 \pm 0.08$ \\
\hline 17 & 432 & 0.7 & 91.7 & 13.5 & $39.63 \pm 0.33 a$ & $0.536 \pm 0.003 b$ & $0.77 \pm 0.04 \mathrm{~b}$ & $<0.75$ & $33.85 \pm 0.48 b$ & $2.75 \pm 0.15 a$ & $1.60 \pm 0.12 a$ \\
\hline 21 & 349 & 0.8 & 125 & 17.3 & $44.88 \pm 1.57 \mathrm{a}$ & $0.582 \pm 0.001 b$ & $0.96 \pm 0.06 \mathrm{~b}$ & $1.00 \pm 0.01$ & $47.28 \pm 1.62 \mathrm{a}$ & $3.41 \pm 0.16 \mathrm{a}$ & $1.81 \pm 0.05 a$ \\
\hline 31 & 93 & 0.9 & 188 & 24.0 & $68.62 \pm 2.09 a$ & $0.928 \pm 0.035 b$ & $1.40 \pm 0.03 b$ & $2.17 \pm 0.09$ & $65.00 \pm 0.51 b$ & $4.92 \pm 0.12 \mathrm{a}$ & $2.12 \pm 0.04 \mathrm{a}$ \\
\hline 35 & 25 & 1.0 & 216 & 41.1 & $77.58 \pm 1.14 a$ & $1.002 \pm 0.105 b$ & $2.24 \pm 0.07 a$ & $2.59 \pm 0.13$ & $77.85 \pm 1.93 a$ & $5.07 \pm 0.45 a$ & $2.28 \pm 0.07 a$ \\
\hline
\end{tabular}

Toc, tocopherol; Pol, polymers; PV, peroxide value; $\mathrm{K}_{232}$, specific extinction at $232 \mathrm{~nm}$. *Group of compounds located in the hydroxydiene region of the chromatograms, probably formed by TAG with one or more acyl chains holding a hydroxy- function and by TAG with more than one acyl chain holding the hydroperoxy- function. ND, not detected. Different letters in the concentrations of each group of compounds for a given sample denote significant differences between the TAG and FAME analyses (p < 0.05). 
Table 3 Analyses of high oleic sunflower oil oxidized at $40^{\circ} \mathrm{C}$ in the dark.

\begin{tabular}{|c|c|c|c|c|c|c|c|c|c|c|c|}
\hline \multirow[b]{2}{*}{$\begin{array}{l}\text { Time } \\
\text { (days) }\end{array}$} & \multirow[b]{2}{*}{$\begin{array}{c}\text { Toc } \\
\text { (ppm) }\end{array}$} & \multirow[b]{2}{*}{$\begin{array}{l}\text { Pol } \\
\text { (\%) }\end{array}$} & \multirow[b]{2}{*}{$\begin{array}{c}\text { PV } \\
(\mathrm{meq} / \mathrm{kg})\end{array}$} & \multirow[b]{2}{*}{$\mathbf{K}_{232}$} & \multicolumn{4}{|c|}{ TAG analysis } & \multicolumn{3}{|c|}{ FAME analysis } \\
\hline & & & & & $\begin{array}{l}\text { Hydroperoxy- } \\
\text { (mmol/kg) }\end{array}$ & $\begin{array}{c}\text { Keto- } \\
\text { (mmol/kg) }\end{array}$ & $\begin{array}{l}\text { Hydroxy-* } \\
\text { (mmol/kg) }\end{array}$ & $\begin{array}{c}\text { Others } \\
\text { (mmol/kg) }\end{array}$ & $\begin{array}{l}\text { Hydroperoxy- } \\
\text { (mmol/kg) }\end{array}$ & $\begin{array}{c}\text { Keto- } \\
(\mathbf{m m o l} / \mathbf{k g})\end{array}$ & $\begin{array}{l}\text { Hydroxy- } \\
\text { (mmol/kg) }\end{array}$ \\
\hline 0 & 630 & 0.5 & 2.4 & 2.3 & $2.53 \pm 0.05 a$ & $0.328 \pm 0.002 b$ & $<0.75$ & ND & $2.55 \pm 0.01 \mathrm{a}$ & $0.41 \pm 0.00 \mathrm{a}$ & $0.24 \pm 0.03$ \\
\hline 10 & 566 & 0.5 & 17.0 & 3.7 & $6.85 \pm 0.25 a$ & $0.376 \pm 0.004 b$ & $<0.75$ & ND & $6.12 \pm 0.05 b$ & $0.50 \pm 0.02 \mathrm{a}$ & $0.36 \pm 0.02$ \\
\hline 21 & 483 & 0.6 & 30.9 & 5.5 & $11.43 \pm 0.13 a$ & $0.430 \pm 0.001 b$ & $<0.75$ & $<0.75$ & $11.42 \pm 0.94 a$ & $0.83 \pm 0.04 a$ & $0.49 \pm 0.00$ \\
\hline 36 & 356 & 0.6 & 57.8 & 8.0 & $17.65 \pm 0.41 \mathrm{a}$ & $0.546 \pm 0.015 b$ & $<0.75$ & $0.75 \pm 0.03$ & $17.84 \pm 0.14 \mathrm{a}$ & $1.43 \pm 0.09 a$ & $0.74 \pm 0.03$ \\
\hline 55 & 158 & 0.7 & 83.9 & 10.4 & $25.97 \pm 0.24 a$ & $0.728 \pm 0.035 b$ & $1.12 \pm 0.14 a$ & $1.87 \pm 0.01$ & $25.79 \pm 0.99 a$ & $1.88 \pm 0.05 a$ & $1.10 \pm 0.02 \mathrm{a}$ \\
\hline 75 & 0 & 0.8 & 115 & 14.2 & $31.88 \pm 1.59 a$ & $0.825 \pm 0.042 b$ & $1.19 \pm 0.06 \mathrm{~b}$ & $3.12 \pm 0.25$ & $31.77 \pm 1.15 a$ & $2.58 \pm 0.02 a$ & $1.59 \pm 0.01 \mathrm{a}$ \\
\hline 82 & 0 & 1.4 & 157 & 21.7 & $34.62 \pm 0.28 b$ & $0.881 \pm 0.008 b$ & $1.26 \pm 0.03 b$ & $6.13 \pm 0.39$ & $39.80 \pm 0.53 a$ & $3.24 \pm 0.06 \mathrm{a}$ & $2.24 \pm 0.02 \mathrm{a}$ \\
\hline
\end{tabular}

For abbreviations see Table 2. Different letters in the concentrations of each group of compounds for a given sample denote significant differences between the TAG and FAME analyses $(\mathrm{p}<0.05)$. 


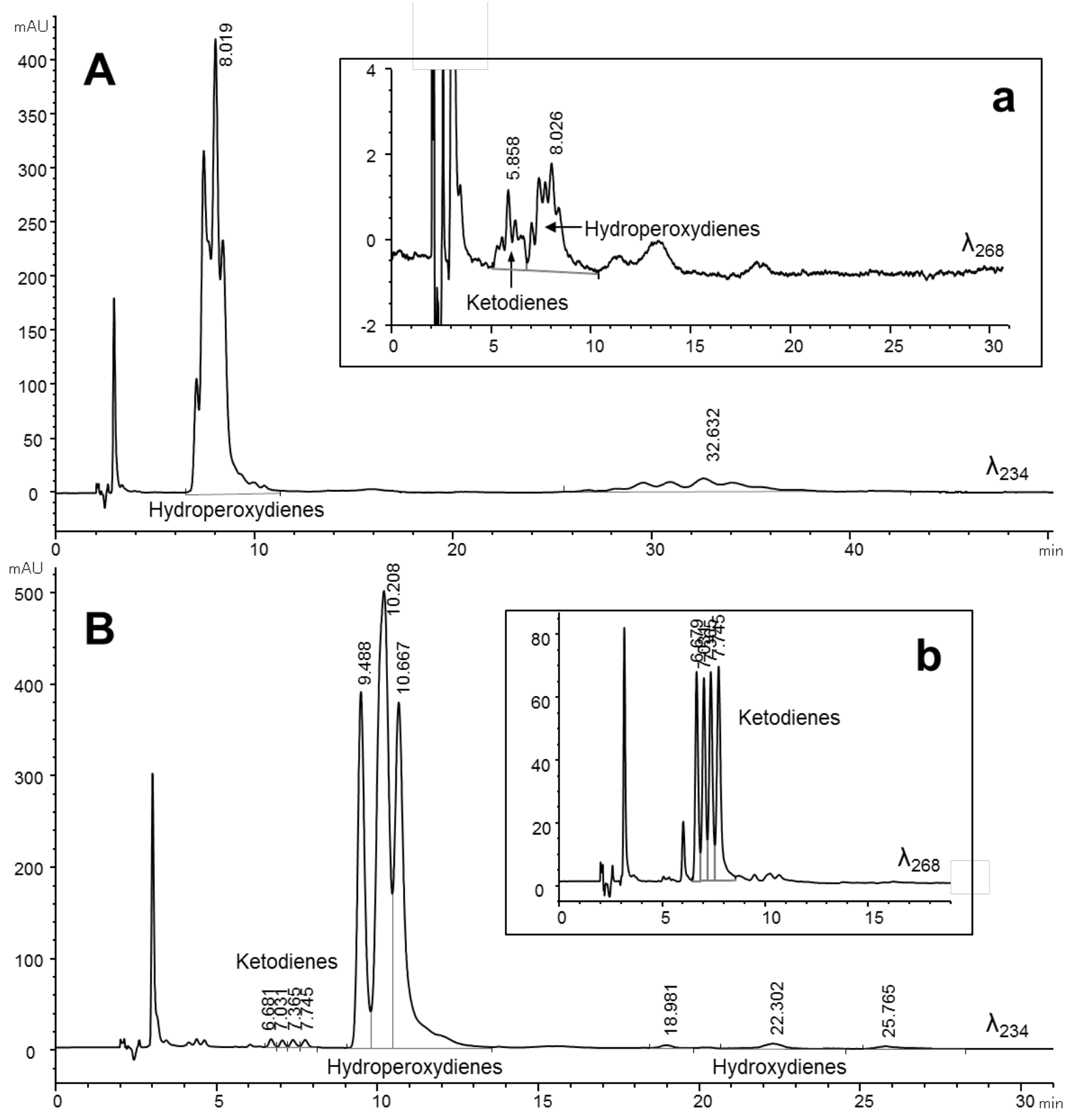

Figure 1 

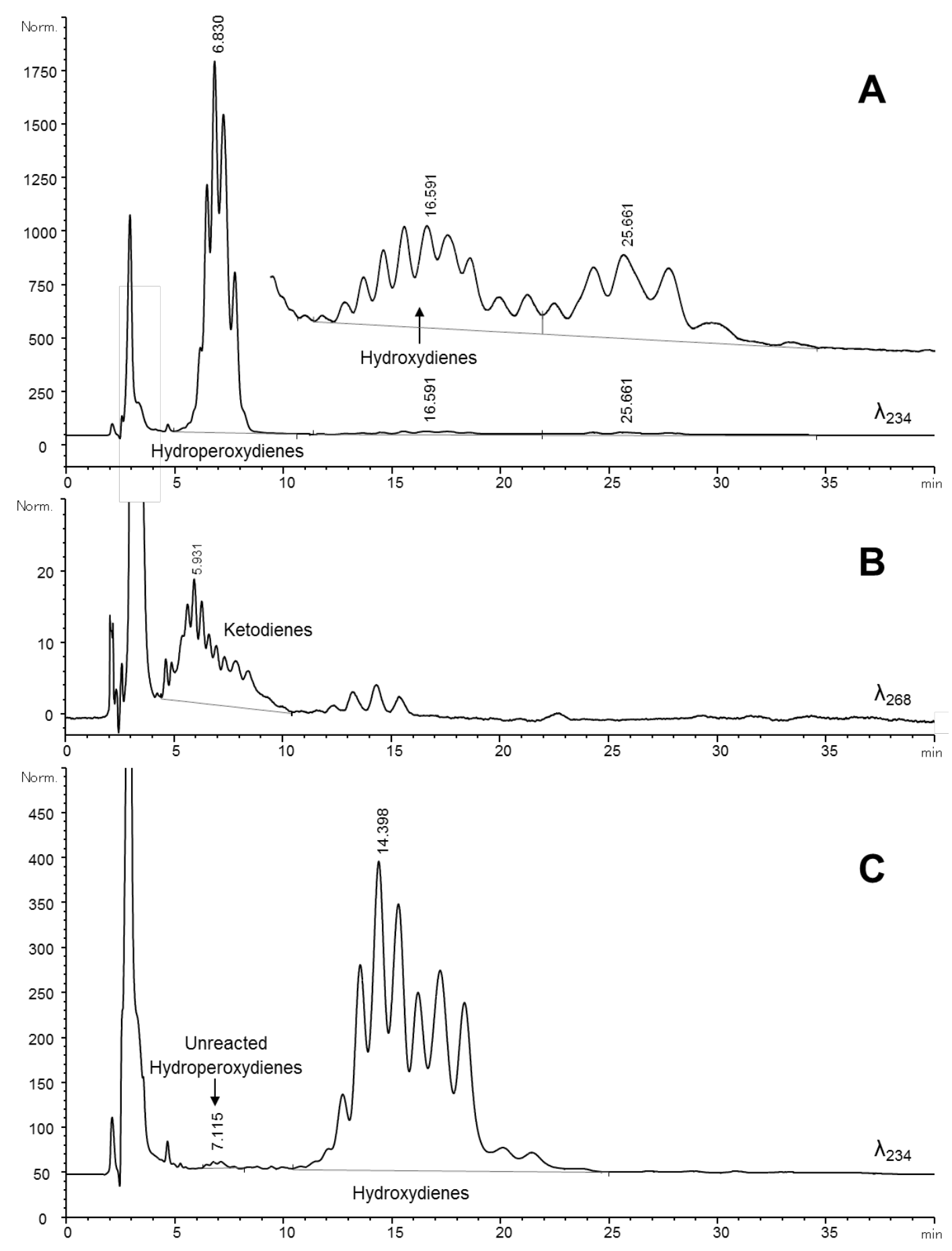

Figure 2 